\title{
CLEAR-AIR LIDAR DARK BAND
}

\author{
Paolo Di Girolamo ${ }^{1}$, Andrea Scoccione ${ }^{2}$, Marco Cacciani', Donato Summa ${ }^{1}$, Jan H. Schween ${ }^{3}$ \\ ${ }^{1}$ Scuola di Ingegneria, Università degli Studi della Basilicata, Italy, Email: digirolamo@unibas.it \\ ${ }^{2}$ Dipartimento di Fisica, Università di Roma "La Sapienza", Italy \\ ${ }^{3}$ Institut fuer Geophysik und Meteorologie, Universität zu Köln, Germany
}

\begin{abstract}
This paper illustrates measurements carried out by the Raman lidar BASIL in the frame of HOPE, revealing the presence of a clear-air dark band phenomenon (i.e. the appearance of a minimum in lidar backscatter echoes) in the upper portion of the convective boundary layer. The phenomenon is clearly distinguishable in the lidar backscatter echoes at $1064 \mathrm{~nm}$. This phenomenon is attributed to the presence of lignite aerosol particles advected from the surrounding open pit mines in the vicinity of the measuring site..
\end{abstract}

\section{INTRODUCTION}

In the frame of the $\mathrm{HD}(\mathrm{CP}) 2$ Observational Prototype Experiment (HOPE), the Raman lidar system BASIL was deployed and operated over the period April-May 2013 in the Atmospheric Supersite JOYCE, located within the Jülich Research Centre (Central Germany, Lat.: 50 $54^{\circ}$ $\mathrm{N}$; Long.: 6 $6^{\circ} 4^{\prime}$ E, Elev. $105 \mathrm{~m}$ ). This site is approximately $3 \mathrm{~km}$ West of the TagebauHambach open-pit lignite mine, which represents the largest operational lignite mine on Earth with a maximum depth of $200 \mathrm{~m}$ (Figure 1). The dump of this mine forms the hill Sophienhöhe which reaches $302 \mathrm{~m}$ and is partially re-cultivated with forest. A second open-pit lignite mine, named Tagebau Inden, is located approximately. $3 \mathrm{~km}$ South-West of the Supersite.

Both mines lie in sectors of $29-114^{\circ}$ (red shaded area in figure 1) and $180-239^{\circ}$ (blue shaded area in figure 1) relative to the location of the Raman lidar. If wind is blowing from these directions, lignite particles from the two open-pit mines or the surrounding hill are lifted up from the ground and transported over the lidar site, with appreciable effects on the measurements.

Evidence of this particle transportation was found in lidar elastic backscatter echoes on a variety of case studies during HOPE, with the appearance of a specific odd feature in the upper portion of the convective boundary layer (CBL). Specifically, a minimum in lidar backscatter echoes at $1064 \mathrm{~nm}$, with a backscatter reduction of approximately 1 $\mathrm{dB}$, is observed. This feature is found to have a vertical extent of approximately $100 \mathrm{~m}$ and persist over a period of several hours, with an alternation of intensifications and attenuations of the phenomenon. A similar feature with a comparable temporal duration and backscatter reduction had been first reported by [1] in the presence of light precipitation events; this phenomenon, referred to as lidar dark band, had been demonstrated to be ascribable to the changes in scattering properties of precipitating particles taking place during the snowflake-to-raindrop transition in the proximity of the melting level.

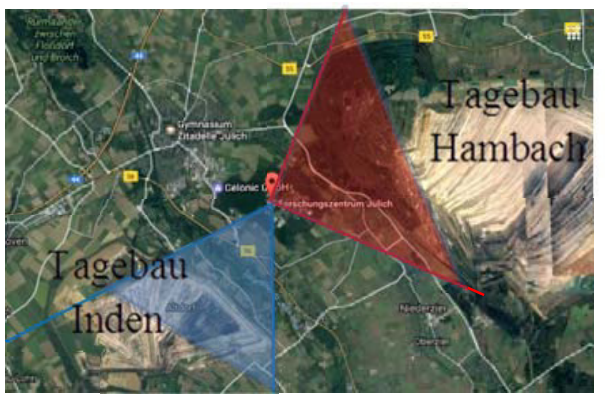

Figure 1: Locations of the Raman lidar system BASIL within the Jülich Research Centre (pink dot), the two open-pit lignite mines Tagebau Hambach and Tagebau Inden, and the hill Sophienhöhe.

Instead, the phenomenon reported in the present research effort appears in clear-air conditions and in the presence of strong convective activity in the boundary layer: we will refer to it in the following as to the clear-air dark band phenomenon or the convective dark band phenomenon. In this paper we provide experimental evidence and a possible interpretation for the occurrence of this phenomenon. 


\section{RESULTS}

Figure 2 illustrates the time-height cross-section of the range-corrected backscatter signal at 1064 $\mathrm{nm}, R C S_{1064}$, as measured by BASIL (upper panel), and the vertical wind speed, as measured by the Univ. of Cologne wind lidar (lower panel), in the time interval 12:00 - 13:00 UTC on 18 April 2013. For the purpose of these measurements, the two lidars were located within a distance of $80 \mathrm{~m}$. The upper panel of the figure clearly reveals the presence of a significant aerosol loading within the boundary layer, which is tracing the presence of a well-mixed and quasistationary CBL at this time of the day, extending up to approximately $2000 \mathrm{~m}$. The figure also reveals the presence of alternating updrafts and downdrafts. The largest variability of $R C S_{1064}$ is observed in the interfacial layer, as a result of the penetration of aerosol-rich air rising from the ground and the entrainment of aerosol-poor air sinking from the free troposphere.

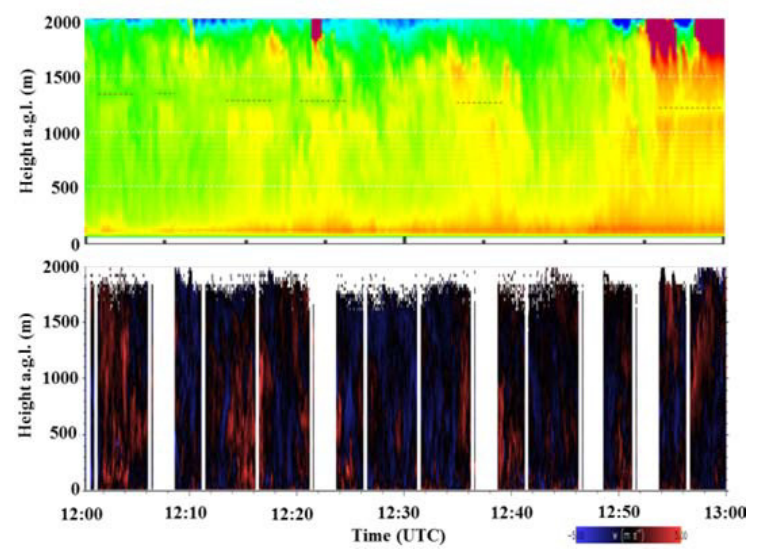

Figure 2: Time-height cross-section of $R C S_{1064}$ (upper panel, with the black dashed line highlighting the presence of the backscatter reduction) and the vertical wind speed (lower panel) in the time interval 12:00 13:00 UTC on 18 April 2013. RCS 1064 is expressed in arbitrary units with low to mid to high values represented with blue to green to red.

A persistent minimum in lidar backscatter is observed around $1200 \mathrm{~m}$, with alternating intensity fluctuations. This minimum persist albeit clear presence of up-drafts (orange eddies, with positive vertical wind speed values) and downdrafts (blue eddies, with negative vertical wind speed values), and thus cannot be related to a layered structure of aerosol in the mixing layer. Note that the backscatter minimum occurs preferably during up-drafts, but not during downdrafts. This behavior is clearly highlighted in figure 2, where the black dashed lines indicating the lidar backscatter minima only appear in temporal coincidence with the vigorous updrafts, testified by the positive vertical speed values (up to $5 \mathrm{~m} \mathrm{~s}^{-1}$ ) measured by wind lidar, but do not appear in coincidence with the downdrafts (negative vertical speed values down to $-5 \mathrm{~m} \mathrm{~s}^{-1}$ ).

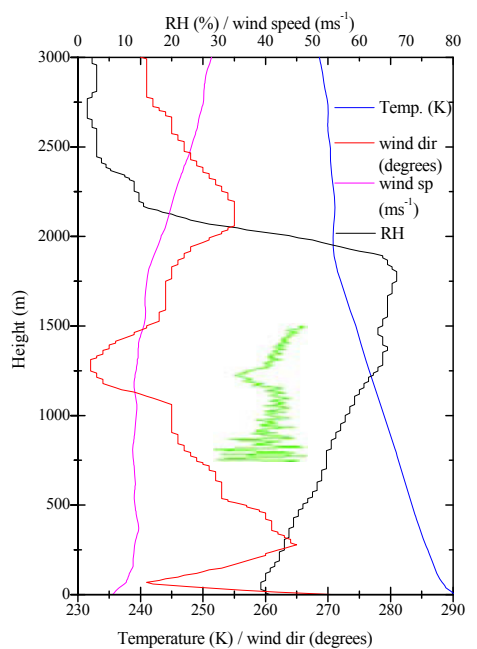

Figure 3: Vertical profile of $R C S_{1064}$, at 13:00 UTC on 18 April 2013 (1 min average, green line), together with the vertical profiles of temperature (blue line), $R H$ (black line) and wind direction (red line) and speed (purple line) as measured by the radiosonde launched from the near-by station of Hambach (4 km E-SE).

Figure 3 illustrates the vertical profile of $\mathrm{RCS}_{1064}$ at 13:00 UTC on 18 April 2013 (1 min average, green line - for the purpose of clarity only shown in the height interval 750-1500 m), together with the vertical profiles of temperature, relative humidity (RH) and wind direction and speed, as measured by the radiosonde launched from the near-by station of Hambach (4 km E-SE). The clear-air dark band is found to extend from 1150 to $1275 \mathrm{~m}$, with a vertical extend of $125 \mathrm{~m}$ and a minimum in lidar backscatter at $1225 \mathrm{~m}$ (backscatter reduction $=17 \%$, corresponding to $0.8 \mathrm{~dB}$ ). This band takes place few hundred meters below both the Lifting Condensation Level (LCL, at $1725 \mathrm{~m}$ or $814 \mathrm{mbar}$ )) and the freezing level (at $1630 \mathrm{~m}$ or $823.2 \mathrm{mbar}$ ). The figure reveals that wind is blowing from directions in the interval from $265^{\circ}$ at surface to $232^{\circ}$. More 
specifically, the lidar backscatter reduction is located in the same height region (1125-1450 m) where wind is found to blow from directions in the interval $232-239^{\circ}$, i.e. from the directions where the Tagebau Inden open-pit lignite mine is located. CBL wind direction measurements from radiosondes may be difficult to interpret as they may reflect rotations taking place within the convective plumes. However, similar values (236$242^{\circ}$ ) in the same height interval are also present in the $1 \mathrm{~h}(12: 00$ - 13:00 UTC) average profile measured by the wind lidar (not shown here), with values throughout the whole profile from $270^{\circ}$ (at surface) to $230^{\circ}$ (at $1600 \mathrm{~m}$ ).

Figure 3 also reveals that the air at this height is characterized by RH values in the range $60-62 \%$. Lignite particles advected by the wind on the lidar site are captured and ingested within the updrafts and downdrafts associated with the intensive convective activity present at the lidar site. As a result of the adiabatic cooling, air-parcels undergo a sudden RH increase from values in the range 60$62 \%$ (this being the environmental RH value at the base of the dark band) to values in the range $75-80 \%$ (these latter are the values reached within the lifting air-parcel assuming an ideal adiabatic cooling with no air entrainment into the convective plumes or external air within the lifting air-parcel). This sudden increase of RH has important effects on the size growth of the uplifted lignite aerosols.

Most clear-air dark band observations we collected in the absence of a cloud topped CBL. However, clouds in the upper portion of the CBL are observed in figure 2 at 12:53-13:00 UTC (orange-brown features in the upper panel).

\section{HYGROSCOPIC AND SCATTERING BEHAVIOR OF LIGNITE PARTICLES}

Dried lignite particles produced in open pit lignite mines have a very marked hygroscopic behavior $[2,3]$, and, as a result of this behavior, effectively absorb moisture from the atmosphere. Measurements of particle size distribution of lignite particles escaped from heavy industrialized areas (mining and power stations operations), in the form of fly ash or fugitive dust, have been reported by several authors (among others, [4]; [5]). Specifically, [4] were able to measure the particle size distribution of fly ash injected into the atmosphere from elevated stacks in power stations, with a prominent mode at approximately $8 \mu \mathrm{m}$ and with about $80 \%$ of the particles smaller than $10 \mu \mathrm{m}$. Civiš and Hovorka (2010) [5] reported size distribution measurements for brown coal with an average particle size of $1.84 \mu \mathrm{m}$. All these authors revealed a limited degree of polydispersion for atmospheric lignite particles. Considering a log-normal size distribution, the degree of poly-dispersion or width of the particle distribution is expressed in terms the percentage standard deviation of the $\log$ of the distribution. Specifically, in [4] a percentage standard deviation $\sigma$ of $16 \%$ is reported. A narrower size distributions has been reported by [5], with $\sigma$ equal to $5 \%$.

The solution effect typically dominates hygroscopic particles' growth when the radius is small (smaller than the critical radius $r_{c}$ ), which results in small solution droplets being in equilibrium with water vapour at $\mathrm{RH}$ values less than $100 \%$. At this stage, small increases in RH determine small droplet size growths until equilibrium is newly reached. This mechanism is possibly responsible for the lignite particle growth below the LCL, ultimately leading to the appearance of a minimum in lidar backscatter echoes (i.e. the above mentioned clear-air dark band phenomenon). The above derived $\mathrm{RH}$ change from $60-62$ to $75-80 \%$ would accordingly result in a particle growth by $\sim 15-30 \%$. In this study, we are considering an initial size for the dry lignite particles of 1.84 and $8 \mu \mathrm{m}$, as reported by Civiš and Hovorka (2010) [4] and Triantafyllou et al. (2006) [5], respectively, based on measurements of dust samples from surface lignite mines (see more details in section 3).

Scattering properties of lignite particles have been simulated based on the application of a light scattering code for spheres using Mie theory (http://philiplaven.com/mieplot.htm). In order to properly simulate these scattering processes, accurate information on particle refractive index are required, besides those on particle size distribution already provided above. Accurate measurements of lignite refractive index have been reported by Lohi et al. (1992) [6], who observed values of the real and imaginary part of the complex refractive index of 1.70 and $1 \times 10^{-6}$, respectively. Simulations of the scattering 
properties of lignite particles are illustrated in figure 4. Results are expressed in terms of backscattering efficiency $\mathrm{Q}_{\text {back }}$ as a function of particle radius. These simulations are obtained considering a log-normal size distribution, with a value of $\sigma$ of $5 \%$. The simulation in the upper panel of the figure considers a minimum radius of $1.84 \mu \mathrm{m}$, as given by [4], while the simulation in the lower panel considers a minimum radius of 8 $\mu \mathrm{m}$, as given by [5]. Both simulations consider a sounding wavelength of $1.064 \mu \mathrm{m}$, which is the laser wavelength used for the dark band lidar measurements illustrated in figure 2. Results illustrated in this figure 4 reveal that, for specific minimum radius values (for example, $2.4 \mu \mathrm{m}, 3.8$ $\mu \mathrm{m}, 16.5 \mu \mathrm{m}, 28 \mu \mathrm{m}, 40 \mu \mathrm{m})$, a reduction in backscatter efficiency of approximately $1 \mathrm{~dB}$ is observed for a particle size growth by $15-30 \%$, as the one experienced by lignite particles during their adiabatic ascent. Thus, we believe that the observed dark band is related to the oscillations of the backscatter efficiency, ultimately leading to Mie back-scattered signal intensity fluctuations.

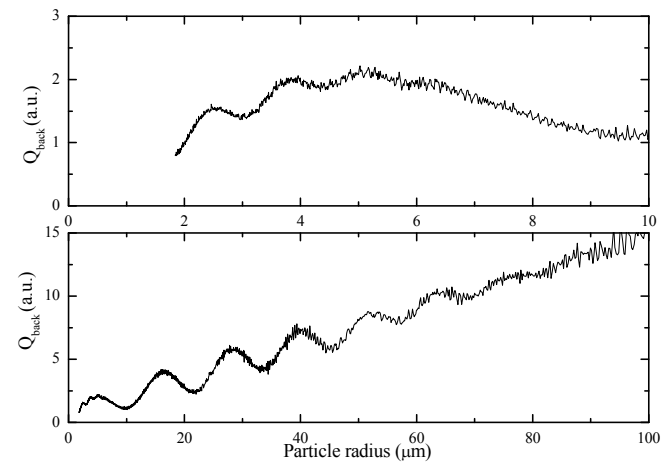

Figure 4: Simulations of the backscattering efficiency as a function of particle radius for lignite particles.

The growth of particles to equilibrium size associated with increasing $\mathrm{RH}$ can be continued up to a RH of $100 \%$ and slightly beyond. Cloud formation at the top of the CBL can take place above the LCL if critical saturation ratio, corresponding to the peak of the Koehler curve, is reached. The critical saturation ratio is typically reached for super-saturation values in the range $0.05-1 \%$, depending on the composition (and consequently the level of hygroscopicity) and size of the aerosol particle acting as condensation nuclei. In the case of lignite particles, typical values of critical radius, $r_{c}$, and saturation ratio, $S_{c}$, are in the range $0.1-10 \mu \mathrm{m}$ and $0.05-1 \%$, respectively. Up to this point $\mathrm{RH}$ has to be increased for the droplet to grow. However, if $\mathrm{RH}$ slightly exceeds the critical saturation ratio, the particle is enabled to grow beyond the critical radius and its critical saturation ratio falls below $\mathrm{S}_{\mathrm{c}}$. As a consequence, the vapour condensates on the droplet, which will continue to grow without the need for further increase in the saturation ratio. When this occurs, clouds can form on the top of the CBL. These processes are responsible for the clouds observed in the upper portion of the CBL at 12:53-13:00 UTC (orange-brown features in the upper panel of figure 2). In the clouds, the droplet growth process does not continue indefinitely as many droplets are present and all of them compete for the same available water vapour.

\section{DISCUSSION}

Dark bands are observed in lidar backscatter echoes in the upper portion of the CBL. These bands appear in clear sky conditions characterized by strong convective activity and are mostly confined to updrafts. Adiabatic cooling within the updrafts leads to an RH increase and a consequent particles' growth, especially of hygroscopic particles. If we assume that most of the particles we observe are hygroscopic lignite particles from the surrounding lignite open-pit mines and their size distribution is mono-disperse or very narrow, we must conclude that the observed dark band is related to the oscillations of the backscatter efficiency as described by Mie-theory, ultimately leading to intensity fluctuations of the Mie backscattered radiation. If the particle size distribution would be less narrow the backscatter oscillations would smear out if not disappear.

The fact that the dark band is confined to the updrafts could be explained in two ways: either the adiabatically warming and thus decrease in $\mathrm{RH}$ in down-drafts does not lead to an inversion of the particle growth, i.e. there is a hysteresis and humidified particles do not evaporate the water they took up during their way up. Or down-drafts transport other particles than the up-drafts. These particles might be less hygroscopic and thus change their size less with RH. Alternatively their size probability distribution function might be not as narrow as in the updrafts resulting in a smear 
out of the oscillations of the backscatter efficiency.

\section{References}

[1] Sassen, K. and Chen, T., 1995: The lidar dark band: An oddity of the radar bright band, Geophys. Res. Lett. 22, 3505-3508.

[2] Lignites of North America, Volume 23

[3] Krawczykowska, A., Marciniak-Kowalska, j., 2012: AGH Journal of Mining and Geoengineering, vol. 36, No. 4, 57-65.
[4] Triantafyllou, A. G., Zoras, S., Evagelopoulos V., 2006: Particulate matter over a seven year period in urban and rural areas within, proximal and far from mining and power station operations in Greece, Environ. Monitor. and Assess. 122, 41-60.

[5] Civiš, M., and Jan Hovorka, J., 2010: Characterization of main dust samples from a surface lignite mine using a resuspension chamber, J. Res. Applic. Prof. Security.

[6] Lohi, A., Wynnyckyj, J. R., Rhodes, E., 1992: Spectral measurement of the complex refractive index of fly ashes of canadian lignite and subbituminous coals, Can. J. Chem. Eng. 70, 751758. 